\title{
Static \& Dynamic Research of Composite Blade using Condition Monitoring Method
}

\author{
Akshay A. Hake, Nagesh S. Ronge, Vijay A. Bhingare, Avinash K. Parkhe, Pradnya K. Bhuse, \\ Sanjay N.
}

\begin{abstract}
The use of composite materials has been increased in different industries like civil, mechanical, aerospace engineering due to their better properties. The rotating blade plays an important role in engineering structures such as turbine blades, airplane propellers, and helicopter blades. This deals with static analysis of composite blade to estimate the material uncertainty by measuring the deflection. The composite blade is fixed like a cantilever beam. To measure this deflection the Hall Effect Sensor is developed which is non contact device works on magnetic field. If magnet is come in front of sensor it creates magnetic field between them and that change in voltage or field is calibrated in terms of deflection of blade. The same process is carried for all the blades to check their uncertainty present in it. Also, it is deals with the dynamic analysis of blade to check their behavior in the axis under rotating condition for different RPM. The acceleration is considered as performance parameter to check the behavior of blade. Also, the setup is developed for accelerations measurement GY-521 Accelerometer. The accelerometer has kept at free end of blade and accelerations are taken in three directions for each rpm and it is represented in a graphical form. The analysis is carryout for both damaged and undamaged blade. The both studies are carried out using condition monitoring approach to observe their behavior of blade in static \& dynamic condition before used in any application.
\end{abstract}

Keywords: Uncertainty, Hall Effect, Static, Dynamic, GY-521, Arduino, Accelerations.

\section{INTRODUCTION}

This deals with static analysis of composite blade to estimate the material uncertainty. The deflection is measured to check the uncertainties present in material. The composite blade is fixed like a cantilever beam. To this deflection the Hall Effect Sensor is developed which is non contact device works on magnetic field. If magnet is come in front of sensor it create magnetic field between them and that change in voltage or field is calibrated in terms of deflection of blade. The same process is carried for all the blades to check their uncertainty present in it. Also, it is deals with the dynamic analysis of blade to check their behavior in the axis under rotating condition for different RPM. The acceleration is considered as performance parameter to check the behavior

Revised Version Manuscript Received on 10 September, 2019.

Akshay A. Hake, SVERI's, College of Engineering, Pandharpur, Maharashtra, India.

Nagesh S. Ronge, SVERI's, College of Engineering, Pandharpur, Maharashtra, India.

Vijay A. Bhingare, SVERI's, College of Engineering, Pandharpur, Maharashtra, India.

Avinash K. Parkhe, SVERI's, College of Engineering, Pandharpur, Maharashtra, India.

Pradnya K. Bhuse, SVERI's, College of Engineering, Pandharpur, Maharashtra, India. India. of blade. Also, for accelerations measurement, the setup is developed using GY-521 Accelerometer and Arduino. The accelerometer has kept at free end of blade and rotates it for different rpm. During rotating condition accelerations are taken in three directions for each and results are represented in a graphical. This study is carried out for both damaged and undamaged using the same parameter. $[1,2,3]$

The researches have been conducted on composite blades. Ronge et al. presented experimental setup for damage identification of rotating blade for both damaged and undamaged using health monitoring approach. Kachareet. al represented the measurement of acceleration using dynamic setup. Kachareet. al presented theory of health monitoring of blade and parameters related to same. The proposed approach is further extended to study large deflection behavior of an initially curved cantilever beam subjected to distributed and combined load. These results are successfully validated with existing results for straight beams and some new results are furnished for initially curved cantilever beams. Mohammad Dado et al. studied the very large deflection behavior of prismatic and non-prismatic cantilever beams subjected to various types of loadings. The formulation is based on representing the angle of rotation of the beam by a polynomial on the position variable along the deflected beam axis. Beléndez, T. et al. presented the classical problem of deflection of a cantilever beam of linear elastic material, under the action of a uniformly distributed load along its length (its own weight) and an external vertical concentrated load at the free end, is experimentally and numerically analyzed. We present the differential equation governing the behavior of this system and show that this equation, although straightforward in appearance, is in fact rather difficult to solve due to the presence of a nonlinear term.

The both static and dynamic studies are carried out using condition monitoring approach to observe the behavior of blade before their use in any application.

\section{INTRODUCTION COMPOSITE BLADE}

The composite blade of uniform cross-section having dimension $800 \times 60 \times 22 \mathrm{~mm}$. This is an eight layer sandwich composite blade. 


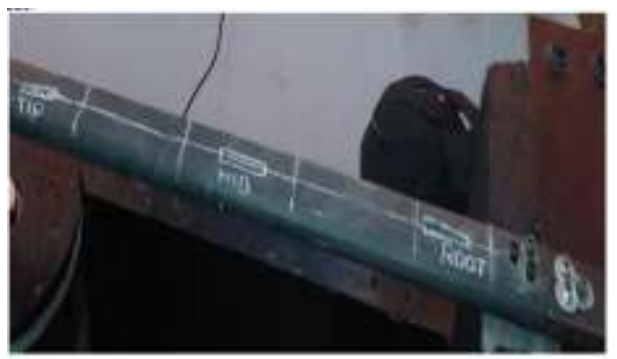

Figure 1Composite blade

Material Properties:

Table1 Material Properties of Composite blade

\begin{tabular}{lccc}
\multicolumn{1}{c}{ Young's Modulus } & $\begin{array}{c}\text { Poisson's } \\
\text { Ratio }\end{array}$ & $\begin{array}{c}\text { Mod. of } \\
\text { Rigidity }\end{array}$ & Density \\
\hline $\begin{array}{l}135 \mathrm{Gpa} \text { (Ex Dir.) } \\
10 \mathrm{Gpa} \text { (Ey Dir.) }\end{array}$ & 0.26 & $5 \mathrm{Gpa}$ & $1600 \mathrm{~kg} / \mathrm{m}^{3}$ \\
$10 \mathrm{Gpa}$ (Ez Dir.) & & & \\
\hline
\end{tabular}

\section{STATIC ANALYSIS OF COMPOSITE BLADE}

\subsection{Hall Effect Sensor \& Arduion (Uno):}

The Hall Effect is an ideal sensing technology. The Hall element is constructed from a thin sheet of conductive material with output connections perpendicular to the direction of current flow. When subjected to a magnetic field, it responds with an output voltage proportional to the magnetic field strength. The voltage output is very small $(\mu \mathrm{V})$ and requires additional electronics to achieve useful voltage levels. When the Hall element is combined with the associated electronics, it forms a Hall Effect sensor. The reasons for using a particular technology or sensor vary according to the application. Cost, performance and availability are always considerations.

Arduion is an open-source platform used for building electronics projects. Arduino consists of both a physical programmable circuit board (referred to as microcontroller) and a piece of software that runs on your computer, used to write and upload computer code to the physical board. We use the Arduino Uno for our study which is one of the more popular boards in the Arduino family and the configuration of it as shown in figure below.
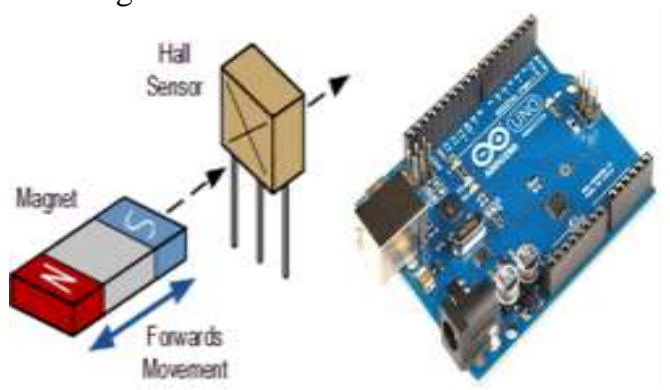

Figure 2 Hall Effect Sensor. Figure 3 Arduino Uno

\subsection{Experimental Analysis:}

Theexperimentation has carried on composite blade for by varying load at free end to find the deflection using Hall Effect sensor. The designed Hall Effect sensor will generate maximum voltage up to 220 volt, if distance between sensor and magnet is up to $6 \mathrm{~mm}$. Initially, we put 1 to $2 \mathrm{~mm}$ distance between sensor and magnet then it shows some voltage will assumed as zero. When $10 \mathrm{~N}$ load is applied at free end of the bladethe voltage difference is generated between initial and final reading. The change in voltage difference is calibrated in terms of deflection of blade. The same process is carried out for other loads ( $20 \mathrm{~N}$ to $80 \mathrm{~N})$ and its voltage differences are calculated using in graphical form which are generated during experimentation.

The experimental setup for the above proposed work and blade in loading and unloading conditionis shown by following figures.

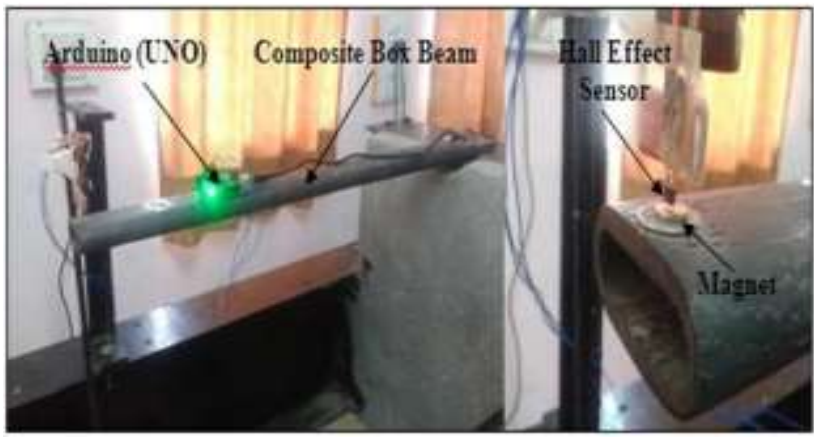

Figure4Experimental setups using Hall Effect Sensor

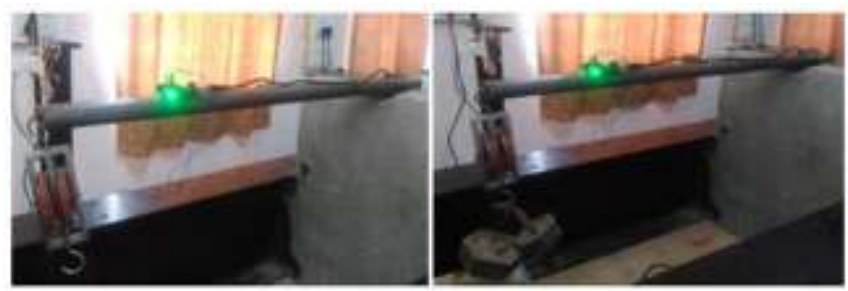

Figure 5Composite blade in unloading and loading condition

During experimentation it has analyzed that for $10 \mathrm{~N}$ load $16 \mathrm{v}$ voltage generated and by using this voltage we calculate the deflection of bladefor this particular load. The same process has carried on four blade. The sample calculations of first bladefor $10 \mathrm{~N}$ and $20 \mathrm{~N}$ loads are given below.

1) Sample calculation for $10 \mathrm{~N}$ :

$$
\frac{6 \mathrm{~mm}}{220 \mathrm{~V}}=\frac{\delta}{16 \mathrm{~V}}
$$

2) Sample calculation for $20 \mathrm{~N}$ :

Therefore, $\delta=0.43 \mathrm{~mm}$

$$
\frac{6 \mathrm{~mm}}{220 \mathrm{~V}}^{\overline{25 \mathrm{~V}}}
$$

Therefore, $\delta=0.68 \mathrm{~mm}$

The voltage difference in initial and final reading for different loads is shown by following graphs. The following graphs are generated during the experimentation of first blade. The same voltage differences are calculated for remaining three blades by generating the same graphs to find its deflection for different loads. 

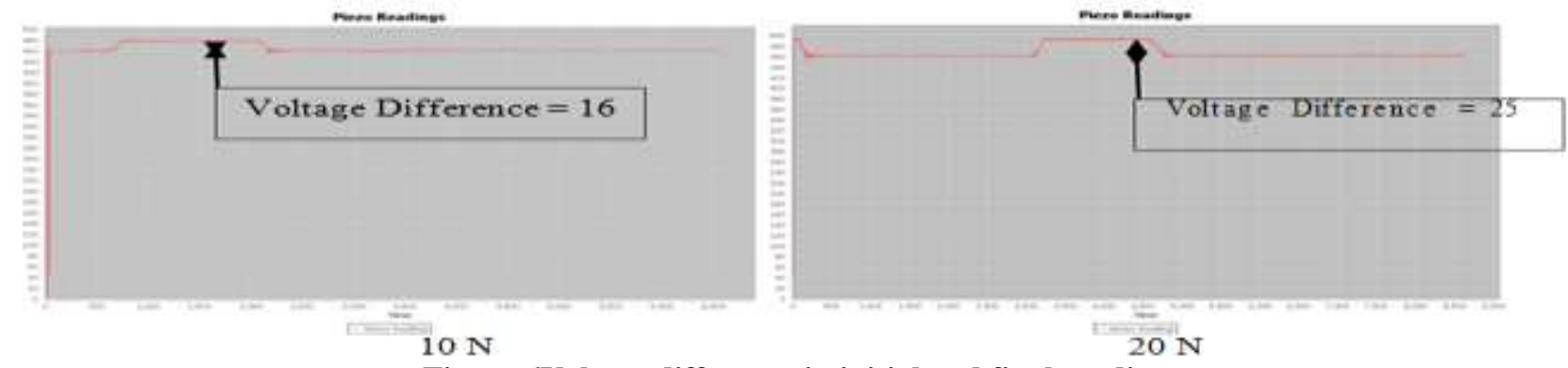

Figure 6Voltage difference in initial and final reading

Table 2 Deflection of composite blade

\begin{tabular}{cccccc}
\hline & & \multicolumn{4}{c}{ Experimental } \\
Sr. & Load & \multicolumn{4}{c}{$\begin{array}{c}\text { Deflection } \\
\text { Nom })\end{array}$} \\
No. & (N) & Blade & Blade & Blade \\
& & 1 & 2 & 3 & 4 \\
\hline 1. & 10 & 0.43 & 0.40 & 0.43 & 0.38 \\
2. & 20 & 0.68 & 0.68 & 0.62 & 0.73 \\
3. & 30 & 0.95 & 1.00 & 0.95 & 0.98 \\
4. & 40 & 1.36 & 1.30 & 1.39 & 1.36 \\
5. & 50 & 1.63 & 1.66 & 1.69 & 1.58 \\
6. & 60 & 1.77 & 1.77 & 1.71 & 1.69 \\
7. & 70 & 2.18 & 2.20 & 2.15 & 2.23 \\
8. & 80 & 2.72 & 2.78 & 2.78 & 2.67 \\
\hline & & & & &
\end{tabular}

Above table represents voltage difference of four composite blade along with its free end deflection for different loads. The experimental results for deflection of four blades for different loads are also shown by following graph.

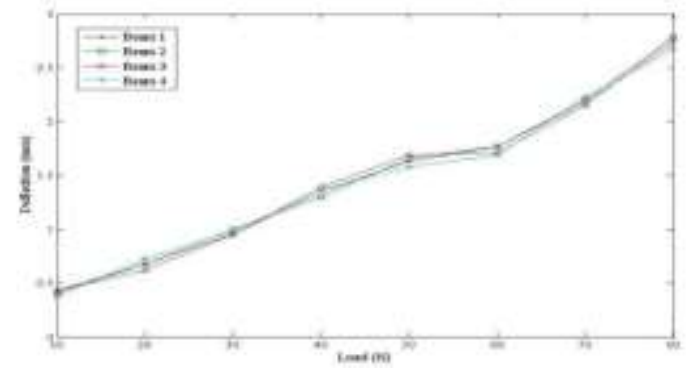

Figure 7 Load Vs Deflection

\section{DYNAMIC ANALYSIS OF COMPOSITE BLADE \& RESULTS}

\subsection{EXPERIMENTAL SETUP FOR ACCELERATION MEASUREMENT:}

The experimental setup for acceleration measurement has shown below. The accelerometer is mounted at free end of

blade with arduino connection shown in figure below.

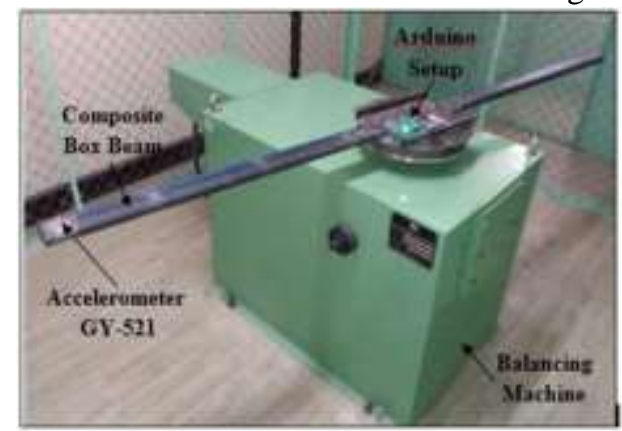

Figure 8 Experimental setup using GY-521 Accelerometer
The blade is mounted on rotating disk and rotating it for different $\mathrm{rpm}$ and using that proposed setup. Here we required to find the accelerations of the rotating beam in terms of $g$ value because the direct reading of sensor is not considered as accelerations, we want to make some conversions or calculations to obtain necessary results only. The values obtained from the GY-521 accelerometer or raw values are used to find the ax, ay, az in terms of $g$ value.. The scaling factor depends on the acceleration limit. Table 1 shows the scaling factors for acceleration limit as per standards available.

Table 3Accelerometer Scaling factors

\begin{tabular}{|c|c|}
\hline Acceleration Limit & Sensitivity or Scaling factor \\
\hline $2 \mathrm{~g}$ & 16384 \\
\hline $3 \mathrm{~g}$ & 8192 \\
\hline $4 \mathrm{~g}$ & 4096 \\
\hline $\mathrm{g}$ & 2048 \\
\hline
\end{tabular}

$$
\begin{aligned}
& \text { Cocrerting the raw data: } \\
& \text { Required valueV }(a x, a y, a z)=\frac{\text { raw value }}{\text { Sensivity V Scaling factor }}(i g \text { value })
\end{aligned}
$$

\subsection{ACCELERATIONS IN UNDAMAGED ROTATING} COMPOSITE BLADE FOR DIFFERENT RPM:

In the first phase the study is carried out for undamaged blade by measuring the acceleration in the direction using the proposed setup. During the rotating condition the movement of blade is taking place in three directions and their results are represented in graphical form which is shown by following
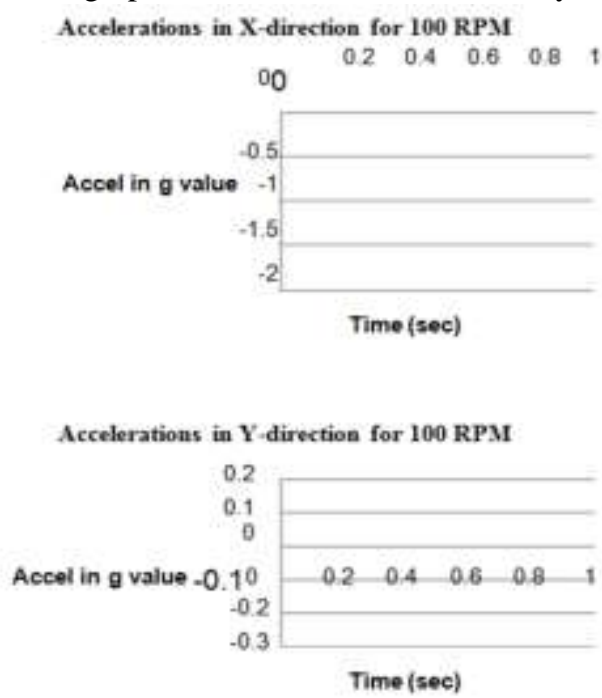

figures.

Published By: 


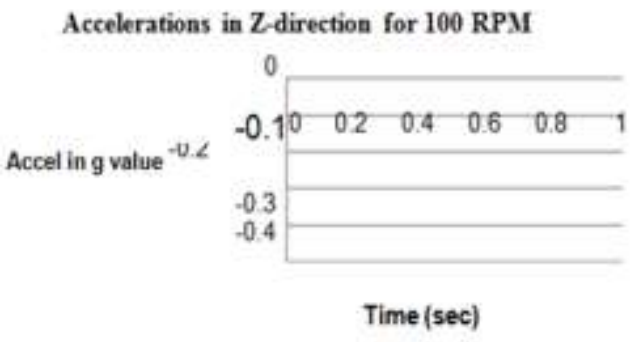

Figure 9Accelerations in undamaged blade $(100 \mathrm{rpm})$

Accelerations in X-direction for $200 \mathrm{RPM}$

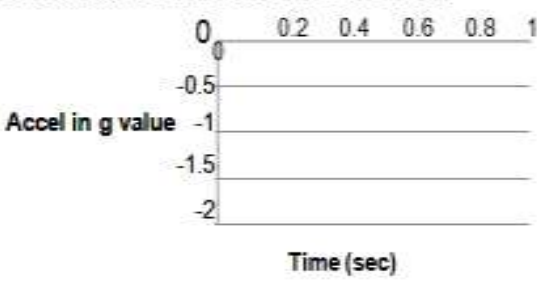

Accelerations in Y-direction for 200 RPM

Accel in g value
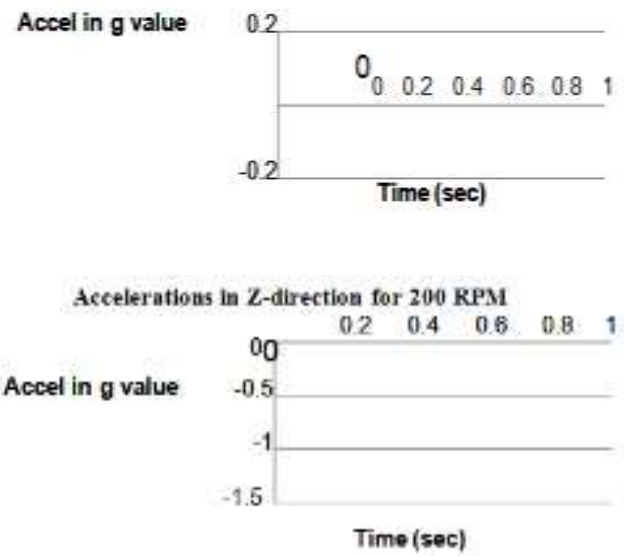

Figure 10 Accelerations in undamaged blade $(200 \mathrm{rpm})$

Figure 9 and 10 shows the accelerations (in $g$ value) in a rotating composite box blade for different $\mathrm{rpm}$. The $\mathrm{X}$-direction represents axial direction, $\mathrm{Y}$ direction represents the horizontal rotating direction of blade and $\mathrm{Z}$ represents the vertical movement of the blade in rotating condition.

4.3 ACCELERATIONS IN DAMAGED ROTATING COMPOSITE BLADE FOR DIFFERENT RPM:

In the 2ndphase similar study is carried out for damaged blade using same process and setup and their results are again represented in following graphical form for different rpm.
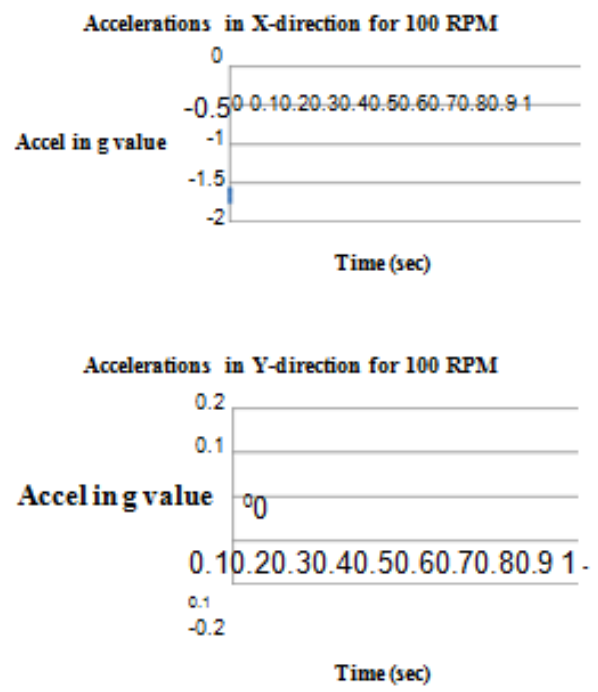

Accelerations in Z-direction for 100 RPM

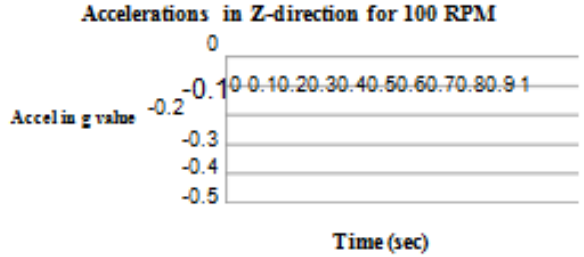

Figure 11Accelerations in damaged blade (100 rpm)
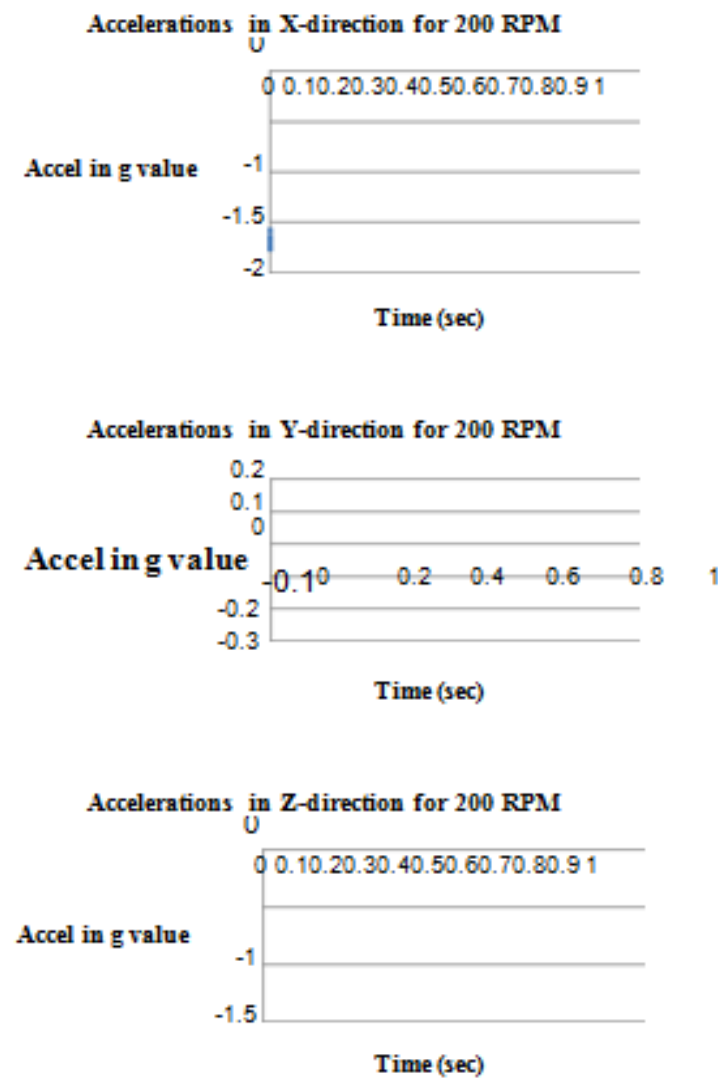

Figure 12 Accelerations in damaged blade (200 rpm) 


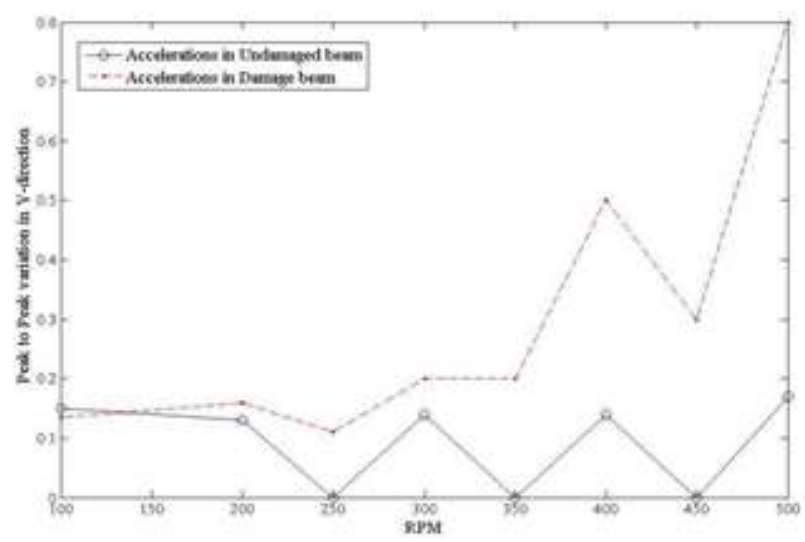

Figure 13 RPM vs accelerations in Y-direction of blade

\section{CONCLUSION}

During the manufacturing of composite material or blades the uncertainties has formed due to some defects or errors manufacturing process and it has studied by the different parameters like deflection, stress, strain, natural frequency etc. The experimentation has carried on composite blade for deflection measurement and this is of for all four blades by the same process and it is carried out to analyze the uncertainty present in material or blade. Also Static and Dynamic analysis was carried out on blade for acceleration measurement. From the above study on composite blade following conclusions are drawn:

The use of dial gauge indicator for deflection measurement will create problems during measurement due its contact with composite blade.

To avoid this situation non contact device is designed and developed for deflection measurement named as Hall Effect Sensor.

As deflection results of all four blades are compared with each other then there is no more difference between them.All the results are near to each other to their respective load is also shown in graphical form.

The acceleration results for damaged and undamaged blade are compared to check the behavior in rotating condition. Using the above graphical results it is observed that the accelerations are increased for damaged blade as their stiffness are get loosed and due to structure of blade get damaged. From the above results and graph the maximum deformation is taking place in $\mathrm{Y}$ direction for the rotating blade.

\section{REFERENCES}

1. RongeBabruvahan, PrashantPawar, and AvinashParkhe,"Experimental analysis of composite rotor blade models for damage identification." In Advances in Science and Engineering Technology International Conferences (ASET), 2018, pp. 1-6.

2. P. S. Kachare, Avinash K. Parkhe, A. A. Utpat, "Free Vibration Analysis of Rotating Composite Box Beam using GY-521 Accelerometer", International Journal of Scientific and Research Publications, Volume 9, Issue 2, February 2019, ISSN 2250-3153.

3. P. S. Kachare, A. K. Parkhe, A. A. Utpat, S. Y. Salunkhe, "Health Monitoring of Static Composite Beam for Material Uncertainty and its Numerical Validation", International Journal of New Technology and Research (IJNTR) ISSN:2454-4116, Volume-5, Issue-3, March
2019 Pages 79-83.

4. SushantaGhuku, KashiNathSaha:: A theoretical and experimental study on geometric nonlinearity of initially curved cantilever beams. In: Engineering Science and Technology, an International Journal, (2015)

5. Mohammad Dado.: A new technique for large deflection analysis of non-prismatic cantilever beams. In: Mechanics Research Communications 32, 692-703, (2005)

6. TarsicioBelendez, CristianNeipp.: Large and small deflections of a cantilever beam. In: European Journal of Physics, Volume 23, (2002)

7. M. Sitar.: Large deflections of nonlinearly elastic functionallygraded composite beams. Archives of Civil and Mechanical Engineering 14, 700-709, (2014)

8. Belendez, T.: Numerical and Experimental Analysis of a Cantilever Beam: A Laboratory Project to Introduce Geometric Nonlinearity in Mechanics of Materials. In: International Journal of Engineering Education, Volume 19, Issue 6, 885-892, (2003). 